\title{
TOWARDS MATCHING ACCESS WITH SUCCESS: USING TECHNOLOGY TO CREATE AN EFFECTIVE LEARNING ENVIRONMENT FOR POSTGRADUATE DISTANCE LEARNING STUDENTS
}

\author{
Karin Müller, Marilize Putter, Milpark Education, South Africa
}

\section{Introduction}

Distance learning has been identified as a key enabler in providing greater access to education. Yet, in order to provide meaningful access and constitute a productive application of both the student and country's resources, such access must include a reasonable chance of success (Department of Higher Education and Training - DHET, 2014). In the South African higher education environment, success - if measured by dropout and throughput rates- has been considerably lower on undergraduate distance learning programmes than on contact learning programmes (DHET, 2018b). On a postgraduate level, the graduation benchmark rate set by government similarly shows a significant disparity between contact and distance learning. For postgraduate qualifications (up to honours level), it is earmarked at $60 \%$ for contact learning; but for distance learning, the target is halved, and set at only $30 \%$ (Ministry of Education - MOE, 2001). These low rates indicate that for many distance learning students, they may have gained access to education, but have a small chance of converting such access into success.

There are many and varied factors that impact on distance learning students' ability to be successful in their studies, ranging from an individual to institutional level. Students who opt for distance learning, often do so at an older age, when they may be mid-career or have families (DHET, 2014), and there is thus a balancing act to be achieved between the competing pressures of work, family life and studies. In a South African context, the political past has left indelible marks on all aspects of society, giving rise to inequality, disadvantage and socio-economic challenges which are further factors to take into account (Subotzky \& Prinsloo, 2011). The diverse profile of the students of the School of Financial Planning and Insurance reflects and is impacted by these factors. The School forms part of Milpark Education, a private higher education institution in South Africa. It offers undergraduate and postgraduate programmes in financial planning and insurance, on a distance learning basis. On the National List of Occupations in High Demand, the roles these students are able to fill or render with greater competence upon completion of their studies are categorised as "highest" and "higher" - descriptions that indicate the level of shortages in the current employment market, and that reflect the historical and anticipated growth rates for these 
occupations (DHET, 2018a). It is therefore critical that as many as possible students are successful at their studies and enter the market equipped with the necessary skills.

In this article, the focus is on the School's Postgraduate Diploma in Financial Planning, which is offered on an honours' level (NQF8). It has been offered as a distance learning programme since inception in 2010. In 2016, the programme was reviewed, and the guiding question was how the qualification could be restructured in order to give effect to the DHET's call for meaningful access, and also to address the factors that challenge distance learning students in their studies. This article is a reflection on the progress made since the introduction of the new model, and how the use of technology has facilitated the successes achieved thus far. For purposes of this article, we have accepted the two-part description of educational technologies of Cleveland-Innes \& Wilton, being firstly, the tools or systems that can be used in education; and secondly, the relationship to its purpose: to solve problems in teaching and learning - as they aptly state, "a tool becomes a technology when it is applied with some intention to meet some human need" (Cleveland-Innes \& Wilton, 2018).

\section{Establishing the context}

\section{Aim of the qualification}

Students study this qualification to obtain specialist knowledge in the various fields of financial planning. A principal aim of the qualification is therefore to equip students with the necessary expertise to work in the financial planning sector, and capably render services to individual and corporate clients (Milpark Education, 2019).

Financial planning is also an interdisciplinary field; sectors as diverse as retirement, health, estates and wealth, asset management, insurance, employee benefits, law and tax are intersected. The qualification therefore serves a second purpose: to enhance the professional expertise and skills of persons employed in related roles in the financial services industry or associated sectors, including investment managers, insurance agents, legal advisers, corporate benefits consultants, pension fund trustees, actuaries, lawyers and accountants whose work environment or interests include financial planning.

Importantly, obtaining the qualification also renders students eligible to write the professional competency exam ( $\left.\mathrm{CFP}^{\circ} \mathrm{PCE}\right)$ of the Financial Planning Institute of Southern Africa (FPI). The FPI is recognised by the South African Qualifications Authority as the professional body for financial planners and is the only institution in Southern Africa who may award the Certified Financial Planner (CFP) designation. The FPI is affiliated to the international Financial Planning Standards Board (FPSB), the body responsible for the certification and promoting of financial planning professional standards in the global community. The $\mathrm{CFP}^{\circ}$ designation is an international accreditation, and is regarded as the highest standard for financial planning professionals. For many, this is the most important drawcard to the qualification: it is a pathway to be recognised as and practice as a Certified Financial Planner Professional. 


\section{Relevance of the qualification}

The qualification's target student population are therefore those who work or wish to enter the financial services industry. The industry is vast and includes different institutions however, central to the function of all role-players, is that financial transactions and financial products are involved, and therefore, individuals, corporates, society in general and the economy of the country are all directly affected and impacted by the financial services industry (Botha et al., 2019). It stands to reason that upskilling those who work in the industry not only produces a better equipped workforce and professionalises the industry, but also improves consumer protection and trust, and leads to the stability of the economy.

In South Africa, financial literacy levels are low (Botha et al., 2019) and the financial education of students addresses these backlogs, which in turn has a ripple effect on the clients and industry they serve. Financial planning, in particular, is described as the process of developing strategies to assist clients in managing their financial affairs, in order to meet their life and financial goals, and become financially independent. (FPI, 2012). Ensuring that clients are financially independent, in the sense of providing adequately for their retirement, health needs and other contingencies, and do not need rely on their families, the state or welfare institutions for support, reveals the important public interest role that financial planning fulfils (Botha et al., 2019).

It was pointed out above that many students seek to ultimately achieve the CFP' designation, for which this qualification meets the education component. Obtaining this designation, may on a personal level, lead to individual growth and better career prospects for students. This is illustrated by a recent study, which found that $80 \%$ of firms in South Africa viewed the designation as favourable when considering candidates for employment; the majority also indicated that they plan to increase the number of $\mathrm{CFP}^{\circ}$ professionals within their firm, whilst $80 \%$ of CFP professionals indicated that they achieve higher rates of career advancement and hold longer terms of employment than their counterparts who do not hold the certification (FPSB, 2013). On a business level, the same study found that CFP' professionals are able to generate higher levels of profit, with $60 \%$ indicating that, as a result of their employment, legal risks and compliance costs were reduced and fewer complaints resulted, with $80 \%$ noting increased client satisfaction and retention (FPSB, 2013). Currently, only 4,744 CFP professionals have been awarded the designation in South Africa (FPSB, 2018), and there is therefore ample room for growth in these numbers in order to efficiently serve the South African population.

Only six higher education institutions have been recognised by the FPI in South Africa as approved education providers. All other institutions other than the School are public universities; and of these, only one offers the qualification via distance learning. The access provided by the School via distance learning to this qualification is therefore crucial in, firstly, ensuring that students are not excluded simply by reason of the fact that they cannot attend 
contact-based learning at universities; and secondly, to increase in the number of candidates eligible to become CFP professionals.

\section{Profile of students enrolled for the qualification}

The student profile on the qualification is becoming more gender balanced, with the number of females enrolled for the qualification currently at $45 \%$ (Figure 1 below). This is promising, as on a previous count, only $30 \%$ of $\mathrm{CFP}^{\circ}$ professionals were women (FPI, 2016). As the demographic distribution reveals, the student profile is also diverse. Particularly encouraging are the student numbers of racial groups regarded as previously disadvantaged (due to racial discrimination policies under the political regime pre-1994), whose entry to education and employment opportunities are critical to address historical imbalances (Figure 2 below).

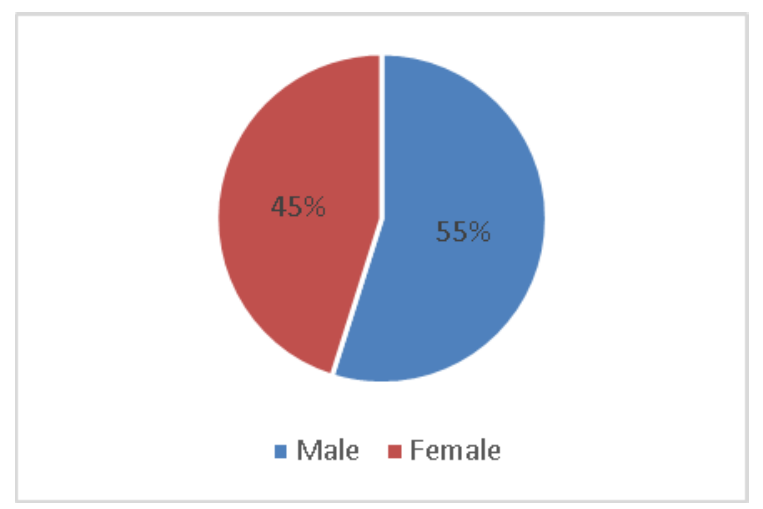

Figure 1. Gender distribution - DLO period: 2017-2018

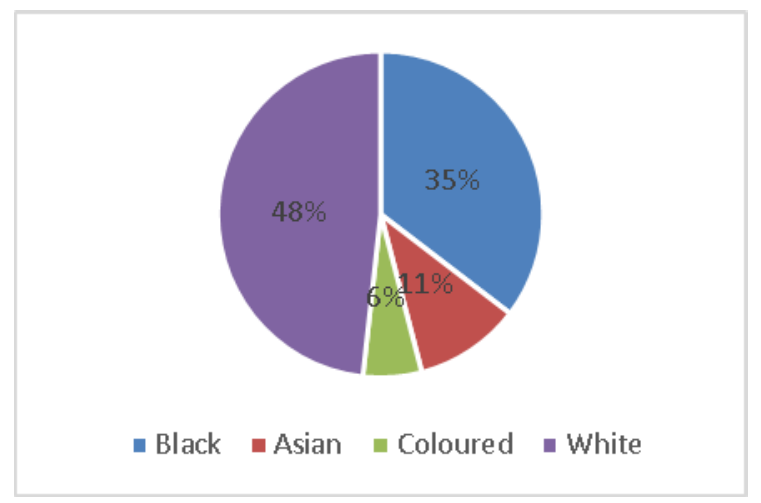

Figure 2. Race Distribution - DLO period 2017-2018

In distance learning, students are typically older, work and study part-time (DHET, 2014), and can be seen as non-traditional students (Stöter et al., 2014; Subotzky \& Prinsloo, 2011). An analysis of the School's student profile correlates with this description. Over the period the postgraduate diploma in its new format has been applicable (this is referred to as the Distance Learning Online period; i.e. the "DLO period"), the biggest group of students fell within the age range of 31-40 years (44\%), followed by $41-50$ years (26\%). Only $23 \%$ of students were younger than 30 years, with $7 \%$ in the highest age group of 51-60 years. The median age of students was 37.62 for 2017, and 35.78 for 2018. Turning to their employment status, the vast majority are employed, with $54 \%$ of students in managerial, supervisory or non-client-facing 


\section{Towards Matching Access with Success: Using Technology to Create an Effective Learning Environment for Postgraduate Distance Learning Students \\ Karin Müller, Marilize Putter}

roles; $39 \%$ in client-facing roles; and the remaining $8 \%$ represent those who are not employed, did not indicate their employment status, or are not active in the financial services industry.

Another factor affecting the profile of the students is the fact that the School subscribes and applies a "recognition of prior learning" policy, so as to promote access to education. Adapting the definition for the School's context, Recognition of Prior Learning (RPL) can be described as the principles and processes through which the prior knowledge and skills of a person are made visible and assessed for the purposes of alternative access and admission (SAQA, 2013). In short, it seeks to address those who may not have had access to formal learning, but have knowledge and skills obtained through life, personal improvement and work experience, and allows for such knowledge and skills to be recognised for the purposes of obtaining access. The School aims to allow at least $10 \%$ of the cohort of students admitted to the qualification as RPL candidates. These candidates are often older and have varied backgrounds, thereby adding to the diversity of the student population. However, as they have not had the formal training up to the required level, support should be embedded, in order to ensure that these candidates can perform on par with other students.

\section{Factors affecting student success}

In its academic policies, the School acknowledges that the following factors can influence a learner's success: academic preparation (i.e. the effectiveness of prior education/learning), adequate financial support, traditional study age, external support system, positive selfconcept, realistic short- and long-term goals, and leadership experience (Milpark Education, 2018).

Taking into account the particular profile of students on the qualification (i.e. as older, working and non-traditional students), it must be recognised that these types of students fall amongst those who are more likely to be faced by barriers to success that arise from nonacademic factors, such as work-related and domestic obligations, than traditional contact learners, and even more so, when there are also socio-economic challenges present (Subotzky \& Prinsloo, 2011). The latter is prevalent in South Africa, given its historical past, and the inequity still remaining holds further challenges for previously disadvantaged groups. Persisting disadvantage in the form of constrained financial resources, geographic distance, literacy (i.e. language and previous schooling), as well as other sociocultural factors, detract from effective and successful studies (Jones et al., 2008).

The various factors specific to studying an online learning environment should also be noted; these include the requirement for a more proactive self-directed approach by the leaner, technical difficulties that may arise, perceived isolation, challenges balancing study, work and family commitments, content misunderstanding, poor academic performance, or a lack of motivation (Amiet et al., 2017). In a South African context, access to technology resources (i.e. devices, data, bandwidth) is also challenging - the cost of communication is high, internet penetration, although the highest on the continent, lags far behind other developing countries for similar income levels, with only half of the population connected, and 
connectivity is also problematic (Gent \& Meyer, 2016; Gillwald et al., 2018). Cognisance should also be taken of digital literacy levels and the divide "not only between the connected and unconnected, but between those who have the skills and financial resources to use the Internet optimally and those barely online" (Gillwald et al., 2018). The DHET refers to this as the "uneven readiness of staff and students", and acknowledges it as a factor to be addressed, when programmes that are internet and technology dependent are submitted for accreditation (DHET, 2014).

\section{Changing for success}

It is against this background that the qualification was reviewed. The changes, as discussed below, were then implemented, so as to transform the offering of the qualification on a distance learning basis (hereafter, referred to as "DL") to a distance learning online (hereafter referred to as "DLO") basis from 2017 onwards.

\section{Time, timing and timetables}

Time, or the lack thereof, is often cited as an important factor in the success and/or dropout rates of a distance learning students (Hachey, Wladis, \& Conway, 2018). It also implicitly points to the competing demands and socio-economic factors that influence distance learning students (Aboo, 2017). Having perceived this to be a factor, it was found that the first semester was over-weighted in comparison to the second, as the modules taken in the first semester had far greater knowledge components. The qualification was initially structured as consisting out of four modules, and a student could elect to take up to two modules per semester. Where students did elect to take two, there was often an overlap of assignments and exams at the same/adjacent intervals. The course structure was therefore not conducive to the effective application of students' available time or their work-life-study balance.

On restructuring the course, the module contents were revised and aligned to the Financial Planning Institute's professional competency profile, which identifies six core financial planning components (FPI, 2012). The result was six credit-bearing compulsory modules, with each module now dedicated to covering a particular practice area, before culminating in the case study module, which synthesises the knowledge and skills of the preceding modules. In addition, one non-credit-bearing induction module was also introduced. Students complete one module at a time, over a period of eights week, and are therefore able to focus all their efforts onto one subject area. (Milpark, 2019). Six cycles are scheduled per year and students therefore have the flexibility to plan their studies around these intakes. This has been made possible by an online admissions program and learning management system.

As part of their studies, students are also required to prepare a proposed study plan (i.e. a timetable), indicating how they plan to approach their studies per week; taking into account their personal and work demands. This connects their studies to their lives in a practical manner. They then receive feedback from the programme manager on their proposed study 
Towards Matching Access with Success: Using Technology to Create an Effective Learning Environment for Postgraduate Distance Learning Students

Karin Müller, Marilize Putter

plan, and have the option to make use of student counselling for further guidance and support.

\section{Interaction, Communication and Connection}

Perceived isolation is cited as another factor that impedes successful studies (Amiet et al., 2017). In order to overcome feelings of isolation, a dedicated online lecturer is assigned to each module, who is an expert in that field of study. The online lecturer is tasked to lead discussions; prompt conversation and debate; and manage the atmosphere of the course. Students are monitored on a weekly basis as to whether they have accessed the course page and have participated in the weekly activity - for students who have not done so, the programme manager establishes contact with them. This in turn ensures a higher hand-in rate, and lessens the chances of students dropping out. The online lecturer's role is aimed at pro-active engagement, not only between students and the institution, and students and their learning material, but also between students themselves.

Such high engagement has been made possible by technology that allows for discussions forums, tutor emails, voice notes, video meetings (via the School's online resources) and even WhatsApp groups (the latter at the initiative of the students), whereby participation is facilitated. The study guide and all related support materials are available online at all times; and this, together with a live classroom (periodically) and recorded video sessions, allows students to be stimulated by different mediums. Moreover, it provides flexibility, as they are able to access and interact with the material, or the online lecturer from any place, and at any time (Milpark, 2018); in addition, the asynchronous structure addresses erratic internet connectivity.

The course is focused on structured learning and each week now has a formative assessment (i.e. an assignment/online test). This ensure that students remain committed. Similarly, assignments are scaffolded so that as students become more competent in their abilities and their knowledge of the material over time, they require less scaffolding or support from their lecturer (Northern Illinois University, 2015). Feedback is critical in order for students to learn from their assessments; however, it must also be provided timeously (Cleveland-Innes \& Wilton, 2018; Conole, 2009). Feedback also bears a correlation to student motivation (Hoskins \& Newstead, 2009). Individualized feedback on formative assessments is provided on a weekly basis. Again, technology has been an enabler: assignments are submitted as well as marked electronically, allowing for flexibility and ease of use on both the students' and lecturers' side. Feedback can now be provided much quicker, as the time delay, costs and logistics of managing manual scripts via postal services has been removed. This promotes the assessment for learning experience.

To address the uneven readiness amongst lecturers, an online training certification course in online lecturing was developed by Milpark Education; and must be completed in order to lecture on distance learning online programmes. For students, an induction programme, which precedes the formal study programme, was introduced. It is offered at no cost to the 
students, so to allow for increased access and the uniform treatment of all students. The induction programme comprises eight weeks, with the first two weeks aimed at familiarising students with the online course environment, the technology to be used, the study programme and the soft skills required to complete their studies (i.e. time management, professional writing, report planning). It also looks at the financial planner and the professional competency framework so to enable students to link their studies to the industry. Students who may not be as digitally literate, are encouraged through continued interaction with the course platform to build their confidence and abilities. Some students may have numeracy and literacy backlogs, some RPL students may not have formal learning in undergraduate tax; other students may not have industry experience and therefore do not have product knowledge. The next six weeks attempt to address these deficiencies, with two weeks dedicated to the development of the maths skills and basic economic theory required; a further two weeks on aspects of taxation within the financial planning environment; and the final two weeks on a products overview. Students who complete the course are able to enrol for the compulsory credit-bearing courses of the qualification.

\section{Integration}

The curriculum of the qualification has been developed taking into account the prescribed knowledge components, abilities and skills for a postgraduate degree level set by the South African Qualifications Authority, and also to align with the competencies of a Certified Financial Planner professional as required by the FPI. Students however need to be able to relate their learning to the workplace environment. The online lecturer is therefore tasked, in a weekly communication, to explain the purpose of the week's work and link it back to practice, so that students understand why it is important and how it fits into the framework of what can be expected of a financial planner. Aside from technology facilitating such communication, it has also allowed the study material to be updated, amended or expanded quickly and relayed to students. As financial planning is affected by various laws, including financial services regulation and tax laws that change frequently, it is imperative that students study the correct and up-to-date material. Moreover, developments in the field (for example, cryptocurrencies as an asset class, robo-advice, or the impact of fintech) can now be swiftly incorporated.

\section{Initial results and feedback}

With the exception of one compulsory module (the final case study module), all modules on the qualification have, over the past two years, been offered four times; i.e. twice per academic year. Throughput on a module level has been monitored. The graph below indicates an improvement on the throughput rate during the period the new DLO model has been applicable, when compared to the previous DL rates: 


\section{Towards Matching Access with Success: Using Technology to Create an Effective Learning Environment for Postgraduate Distance Learning Students \\ Karin Müller, Marilize Putter}

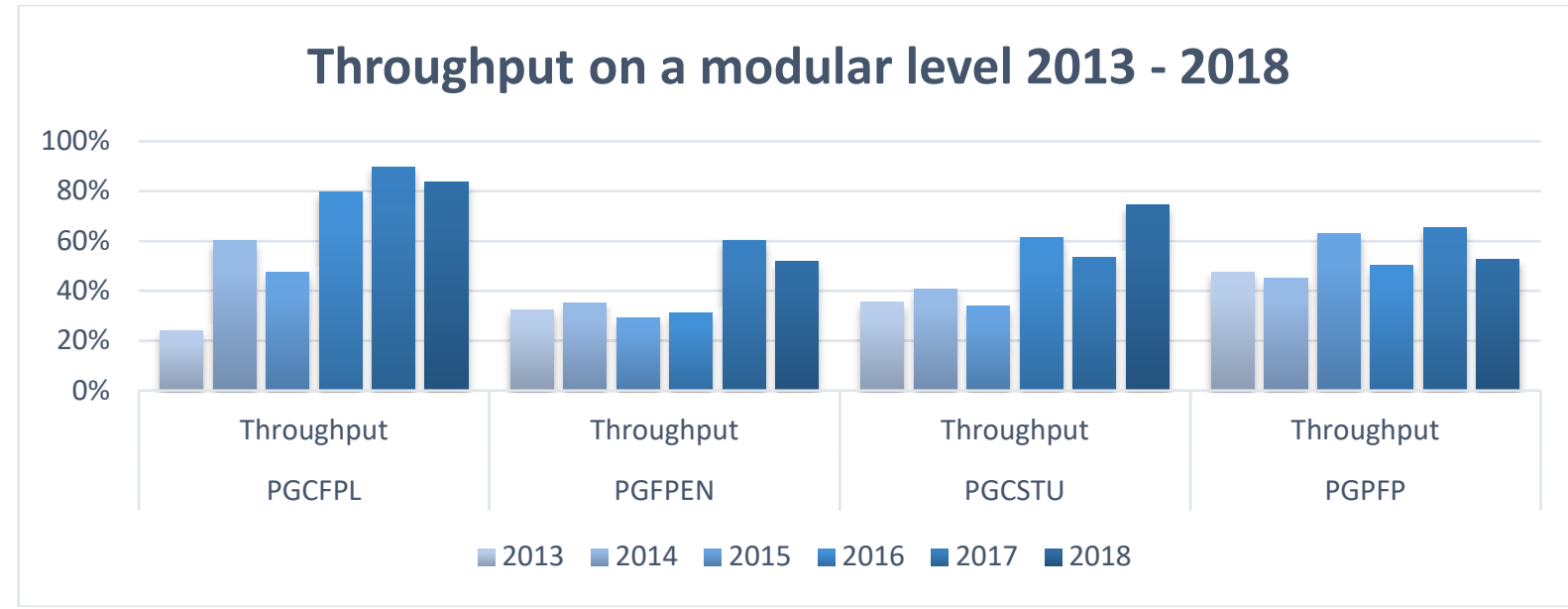

Figure 3. Throughput rates on module level - DL period (2013-2016) and DLO period (2017-2018)

Feedback on recent student surveys are positive about the course model and platform, as these quotes illustrate:

"Compared to the Milpark National Certificate in Financial planning course, I did 7 years ago, this new learning model is light years ahead and I feel I'm am getting much more value and substance in the way of learning and interaction."

"So far the course has been incredible. It is great how all the material is available online and electronically. The way the website and interface are structured is brilliant, it is easy to follow and know what is required for each week."

These two further quotes indicate the importance of interaction and feedback:

"I've thoroughly enjoyed studying this course, and although I'm looking forward to getting the final exam finished I'm going to miss the stimulation of it all."

"The speed at which the lecturers get back to students are admirable. The amount of study material is a lot though. The course has taught me a lot."

In addition, the course structure's positive effect on student motivation becomes evident from the following learner quotes:

"I like the weekly structure of this module. It forces me to do my part every week and every day. Thank you for an excellent program."

"Dividing the work into weekly parts is working nicely. It forces you to do a small bit every day, instead of 500 pages at the end of the 8 weeks." 
Another important indicator has been the learners' performance on the independent professional competency exams for certified financial planners $\left(\mathrm{CFP}^{\circ}\right)$. As these exams only take place in February and August, students who complete their postgraduate diploma via the new DLO model would, depending on their date of completion, have been able to sit for the past three CFP $^{\circ}$ exam sessions. The results for the last CFP exam held in February 2019 is at date of writing not yet available. The results for the February 2018 and August 2018 exams have been encouraging: on each occasion, the School's pass rate has surpassed all other educational providers, including public universities and those who offer the qualification via contact learning. For the February 2018 exam, the School's pass rate was double the national pass rate. For the August 2018 exam, the school's pass rate was $73 \%$ on its candidates who sat for the exam, which was well above the national pass rate of $57 \%$.

\section{Conclusion}

In this article, we have reflected on the need to turn access into success for distance learning students, particularly on a postgraduate level and as it relates to financial planning students in a South African context. More closely, some of the factors inhibiting success were identified, and it was considered how these were addressed when the postgraduate diploma in financial planning was restructured and presented in a distance learning online format. There are indications that technology has indeed served as a tool to alleviate these problems, as indicated by the improved throughput rate, positive student survey feedback and the aboveaverage performance of our students on the external professional competency exams. The latter shows that technology has, to a certain extent, levelled the playing field, in that distance learning students are able to perform as well as (or better than) contact learning students.

The new model has, however, only been in force for the past two years, and thus some aspects can therefore not be fully assessed - for example, the throughput rate on a qualification level can only be assessed after three years and there is still limited comparative professional competency exam results available for the DLO period. It is also still an adaptive process: student surveys and polls raise aspects that require further intervention. To name but a few: ad hoc connectivity problems to the online portal; online lecturers that become passive; some modules being experienced as heavier than others; inadequate assessment feedback and negative interaction amongst students. These require further consideration and study.

It is submitted that the definition of educational technologies by Cleveland-Innes and Wilton, as discussed in the introduction above (Cleveland-Innes \& Wilton, 2018), implicitly contains a third part: that technology is used; thus denoting an ongoing and continuous process. Our future plans therefore include to continue monitoring the performance of our students, to reflect on the issues the various groups of our student population may experience as detractors to success, to continue reviewing the qualification to ensure it leads to optimal workplace integration, and to seek how and where technology can be applied to further the connection between our students, their learning experience, and ultimately their success. 


\section{References}

Aboo, F. (2017). Non-academic factors contributing towards performance of postgraduate open distance learning accounting students. UNISA, South Africa. Retrieved from http://uir.unisa.ac.za/handle/10500/23393

Amiet, D. L., Holt, C., Lodge, J. M., Shaw, L., McKenzie, S., Roddy, C. \& Garivaldis, F. (2017). Applying best practice online learning, teaching, and support to intensive online environments: an integrative review. Frontiers in Education, 2(November), 1-10.

Botha, M., Rossini, L., Geach, W., Goodall, B., du Preez, L., Rabenowitz, P. (2019). The South African Financial Planning Handbook 2019. Durban: LexisNexis.

Cleveland-Innes, M., \& Wilton, D. (2018). Guide to blended learning. Canada: Commonwealth of Learning.

Conole, G. (2009). Introduction: the 7Cs of learning design framework, 1-33. Retrieved from https://www.slideshare.net/GrainneConole/the-7-cs-of-learning-design

Department of Higher Education and Training (2014). Policy for the provision of distance education in South African universities in the context of an integrated post-school system (Vol. 535). Pretoria: Government Gazette.

Department Higher Education and Training (2018a). National list of occupations in high demand. Pretoria: Government Gazette.

Department of Higher Education and Training (2018b). 2000 to 2015 First time entering undergraduate cohort studies for public higher education institutions. Pretoria: Department of Higher Education and Training. Retrieved from http://www.dhet.gov.za/SitePages/UniversityEducation.aspx

Financial Planning Institute of Southern Africa (2012). Financial Planner Competency Profile. Johannesburg: FPI. Retrieved from https://www.fpi.co.za/documents/Competency_Profile.pdf

Financial Planning Standards Board (2013). FPSB's global value of certification survey (insights into how firms value $\mathrm{CFP}^{\circledast}$ certification- South Africa). Denver, CO: FPSB Ltd.

Financial Planning Standards Board (2018). Infographic. Retrieved from https://www.fpsb.org/wp-content/uploads/2019/02/R2-FPSB-0365-2018-GrowthInfographic-GLOBAL-1.pdf

Gent, P., \& Meyer, I. (2016). The status of ICT in education in South Africa and the way forward. Centurion, South Africa: NECT. Retrieved from http://nect.org.za/publications/technical-reports/the-state-of-ict-in-education-in-southafrica/view

Gillwald, A., Mothobi, O., \& Rademan, B. (2018). Policy paper no. 5, Series 5: The state of ICT in South Africa. Cape Town: Research ICT Africa. Retrieved from https://researchictafrica.net/research/research-papers-and-publications/ 
Hachey, A. C., Wladis, C., \& Conway, K. M. (2018). What factors influence student decisions to drop online courses? Comparing online and face-to-face sections. In A. Volungeviciene \& A. Szücs (Eds.), Exploring the micro, meso and macro. Proceedings of the European Distance and E-learning Network 2018 Annual Conference (pp. 99-107). Genoa, Italy: European Distance and E-Learning Network.

Hoskins, S. L., \& Newstead, S. E. (2009). Encouraging student motivation. In H. Fry, S. Ketteridge, \& S. Marshall (Eds.), A handbook for teaching and learning in higher education: enhancing academic practice | University of Portsmouth (pp. 27-39). New York: Routledge Taylor \& Francis Group.

Jones, B., Coetzee, G., Bailey, T., \& Wickham, S. (2008). Factors that facilitate success for disadvantaged higher education students. Athlone, South Africa: Rural Education Access Programme. Retrieved from http://www.reap.org.za/pieces/reports/pdf/tracking_reports/2008_June_factors_that_facili tate_success.pdf

Milpark Education (2018). Academic Policies. Claremont: Milpark Education.

Milpark Education (2019). Postgraduate diploma in financial planning factsheet. Claremont: Milpark Education. Retrieved from https://www.milpark.ac.za/-/postgraduate-diplomain-financial-planning

Ministry of Education (2001). Draft national plan for higher education in South Africa. Pretoria: Ministry of Education. Retrieved from http://www.dhet.gov.za/HED Policies/National Plan on Higher Education.pdf

Northern Illinois University (2015). Instructional scaffolding to improve learning. Retrieved from https://www.niu.edu/spectrum/archives/scaffolding.shtml

South African Qualifications Authority - SAQA (2013). National policy for the Implementation of the recognition of prior learning. Waterkloof: SAQA. Retrieved from http://www.saqa.org.za/docs/pol/2013/natpol_irpl.pdf

Stöter, J., Bullen, M., Zawacki-Richter, O., \& von Prummer, C. (2014). From the back door into the mainstream. In O. Zawacki-Richter \& T. Anderson (Eds.), Online distance education. Towards a research agenda (pp. 421-458). Edmonton, Canada: AU Press, Athabasca University.

Subotzky, G., \& Prinsloo, P. (2011). Turning the tide: a socio-critical model and framework for improving student success in open distance learning at the University of South Africa. Distance Education, 32(2), 177-193. 